\title{
GAMBARAN TINGKAT PENGETAHUAN DAN STATUS KARIES GIGI PADA SISWA SMP KRISTEN 67 MANADO
}

\author{
${ }^{1}$ Donny A. A. Sambuaga \\ ${ }^{2}$ Paulina N. Gunawan \\ ${ }^{3}$ Max F. J. Mantik \\ ${ }^{1}$ Kandidat Skripsi Fakultas Kedokteran Universitas Sam Ratulangi \\ ${ }^{2}$ Program Studi Pendidikan Dokter Gigi Fakultas Kedokteran \\ ${ }^{3}$ Bagian Ilmu Kesehatan Anak Fakultas Kedokteran Universitas Sam Ratulangi \\ Manado \\ Email: donchakemoceng@gmail.com
}

\begin{abstract}
Children is the main target in health care especially dental and oral care. The case of dental and oral health disorders in children that often happen is dental caries. Dental caries is an infectious disease caused by demineralization of enamel and dentine that is associated with the consumption of cariogenic foods that most kids love. Children's knowledge about dental and oral health should be introduced early on to minimize damage to the teeth and mouth. This study aims to describe the level of knowledge and status of dental caries of students in SMP Kristen 67 Bahu Manado. This research is descriptive research. The population in this study is all students aged 13-15 years old with samples of 59 students. This research was conducted by giving questionnaire and DMF-T examination. The results showed that the students' knowledge about dental and oral hygiene is $94.45 \%$ with the high category. And the results of the DMF-T Index is 2.13 with the low category. The role of parents is needed to provide an understanding of the importance of maintaining dental and oral health in children as well as taking the children on a regular basis to check the teeth and mouth.
\end{abstract}

Keywords: children, knowledge, dental caries

\begin{abstract}
Abstrak: Anak adalah sasaran utama dalam pemeliharaan kesehatan terutama kesehatan gigi dan mulut. Gangguan kesehatan gigi dan mulut pada anak yang sering terjadi yaitu karies gigi. Karies gigi merupakan penyakit infeksi yang disebabkan oleh demineralisasi email dan dentin yang berhubungan dengan konsumsi makanan kariogenik yang paling disukai anak-anak. Pengetahuan anak tentang kesehatan gigi dan mulut harus diperkenalkan sejak dini untuk meminimalisir kerusakan pada gigi dan mulut. Penelitian ini bertujuan untuk mengetahui gambaran tingkat pengetahuan dan status karies gigi pada siswa SMP Kristen 67 Bahu Manado. Penelitian yang dilakukan merupakan penelitian deksriptif. Populasi pada penelitian ini yaitu seluruh siswa yang berusia 13-15 tahun dengan jumlah sampel 59 siswa. Penelitian ini dilakukan dengan memberikan kuesioner serta pemeriksaan DMF-T. Hasil penelitian menunjukkan pengetahuan siswa tentang kebersihan gigi dan mulut yaitu 94,45\% dengan kategori tinggi. Dan hasil Indeks DMF-T sebesar 2,13 dengan kategori rendah.Peran orang tua sangat dibutuhkan dalam memberikan pengertian tentang pentingnya menjaga kesehatan gigi dan mulut pada anak serta mengantar anak secara berkala untuk melakukan pemeriksaan gigi dan mulut.
\end{abstract}

Kata kunci: anak, pengetahuan, karies gigi.

Anak adalah sasaran utama dalam pemeliharaan kesehatan terutama kesehatan gigi dan mulut. Sebagai sasaran utama, anak harus mendapatkan bimbingan secara 
terus menerus demi kelangsungan hidup, pertumbuhan, dan perkembangan fisik mental sosial, termasuk mendapatkan pelayanan kesehatan secara umum dan kesehatan gigi dan mulut. Pendidikan kesehatan gigi merupakan suatu metode untuk memotivasi seorang anak agar memelihara kebersihan mulut mereka. Pengetahuan anak tentang kesehatan gigi dan mulut harus diperkenalkan sejak dini untuk meminimalisir kerusakan pada gigi dan mulut. ${ }^{1}$

Gangguan kesehatan gigi dan mulut pada anak yang sering terjadi yaitu karies gigi. Karies gigi merupakan penyakit infeksi yang disebabkan oleh demineralisasi email dan dentin yang berhubungan dengan konsumsi makanan kariogenik yang paling disukai anak-anak. Terjadinya karies gigi disebabkan oleh bakteri penyebab karies yang terdapat pada golongan Streptococus yang secara kolektif disebut Streptococus mutans. ${ }^{2,3}$ Berdasarkan Riset Kesehatan Dasar (Riskesdas) tahun 2013, indeks DMF-T (decayed, missing, filling-teeth) di Indonesia sebesar 4,6\% yang berarti 460 gigi per 100 orang. Indeks DMF-T pada laki-laki usia 12-14 tahun sebesar 4,1\% gigi yang rusak termasuk kategori sedang, dan pada perempuan usia 12-14 tahun sebesar 4,9\% gigi yang rusak termasuk kategori tinggi. Hasil Riskesdas tahun 2013 berdasarkan kategori karakteristik kelompok usia 12-14 tahun memiliki indeks DMF-T sebesar $1,4 \%$ gigi yang rusak termasuk kategori rendah. ${ }^{4}$

Berdasarkan data di atas dapat dilihat bahwa kesehatan gigi dan mulut masih merupakan masalah terutama bagi anak usia sekolah. Berdasarkan hasil survei awal yang dilakukan peneliti di SMP Kristen 67Bahu Manado, sekolah tersebut belum pernah dilakukan penelitian tentang kesehatan gigi dan mulut. Golongan sosial ekonomi orang tua siswa termasuk menengah kebawah. Untuk itu peneliti merasa tertarik melakukan penelitan tentang pengetahuan dan status karies pada siswa di SMP tersebut.

\section{METODE PENELITIAN}

Jenis penelitian ini berupa penelitian deskriptif dengan menggunakan pendekatan potong lintang. Penelitian ini dilakukan di SMP Kristen 67 Bahu, Manado yang dilaksanakan pada bulan Mei 2015. Populasi pada penelitian ini yaitu seluruh siswa kelas VII - VIII usia 11-14 tahun di SMP Kristen 67 Bahu Manado dengan jumlah 80 siswa. Data diperiksa kembali dan dihitung secara manual kemudian diolah menggunakan program Microsoft Excel dalam komputer.

\section{HASIL PENELITIAN \\ Karakteristik responden}

Terdapat 80 siswa yang menjadi sampel dalam penelitian ini namun, saat hari penelitian siswa yang hadir berjumlah 59 sehingga 21 siswa yang tidak hadir masuk dalam kriteria eksklusi. Penelitian dilakukan pada 59 siswa yang masuk dalam kriteria inklusi dengan jumlah siswa laki-laki yang lebih banyak (51\%) dibandingkan dengan siswa perempuan (49\%) (Tabel 1), dan distribusi berdasarkan karakteristik usia dapat dilihat dalam Tabel 2 .

Tabel 1. Distribusi karakteristik responden berdasarkan jenis kelamin

\begin{tabular}{lcc}
\hline Jenis & (n) & $(\%)$ \\
kelamin & & \\
\hline Perempuan & 29 & 49 \\
Laki-laki & 30 & 51 \\
\hline Total & 59 & 100 \\
\hline
\end{tabular}

Tabel 2. Distribusi karakteristik responden berdasarkan usia

\begin{tabular}{lll}
\hline Usia & $(\mathrm{n})$ & $(\%)$ \\
\hline 11 tahun & 4 & 7 \\
12 tahun & 18 & 30 \\
13 tahun & 20 & 34 \\
14 tahun & 17 & 29 \\
\hline Total & 59 & 100 \\
\hline
\end{tabular}

\section{Tingkat pengetahuan}

Berdasarkan hasil penelitian yang didapatkan, pengetahuan siswa SMP Kristen 67 Bahu Manado tentang 
kebersihan gigi dan mulut dibagi berdasarkan jenis kelamin yaitu 92,42\% pada siswa laki-laki dan 94,65\% pada siswa perempuan dan dikategorikan pada status tinggi (Tabel 3) dan berdasarkan karakteristik umur (Tabel 4) yang diketahui pada umur 11 tahun 93,75\% , pada umur 12 tahun $87,91 \%$, pada umur 13 tahun
90,75\% dan pada 14 tahun 91,62\% yang semuanya termasuk kategori tinggi.

Berdasarkan hasil penelitian yang didapatkan, pengetahuan siswa SMP Kristen 67 Bahu Manado tentang kebersihan gigi dan mulut yaitu 94,45\% yang dapat dikatakan tinggi yang didapat dari hasil skoring 2229.

Tabel 3. Distribusi tingkat pengetahuan berdasarkan jenis kelamin

\begin{tabular}{lccc}
\hline Jenis Kelamin & Total & Tingkat Pengetahuan & Kategori \\
& Skor & & \\
\hline Laki-laki & 1109 & $92,42 \%$ & Tinggi \\
Perempuan & 1098 & $94,65 \%$ & Tinggi \\
\hline
\end{tabular}

Tabel 4. Distribusi tingkat pengetahuan berdasarkan usia

\begin{tabular}{cccc}
\hline Usia (Tahun) & Total Skor & Tingkat Pengetahuan & Kategori \\
\hline 11 & 150 & $93,75 \%$ & Tinggi \\
12 & 633 & $87,91 \%$ & Tinggi \\
13 & 726 & $90,75 \%$ & Tinggi \\
14 & 623 & $91,62 \%$ & Tinggi \\
\hline
\end{tabular}

$$
\begin{aligned}
& \frac{\text { Total jumlah nilai skor responden }}{\text { Jumlah skor tertinggi }} \times 100 \%=\text { hasil } \\
& \frac{2229}{2360} \times 100 \%=94,45 \%
\end{aligned}
$$

Angka : $0-33,3 \% \quad$ : Rendah

Angka : 33,4\% - 66,6\% : Sedang

Angka : $66,7 \%-100 \%$ : Tinggi

\section{Status karies}

Dari hasil pemeriksaan DMF-T pada siswa SMP Kristen 67 Bahu Manado, total indeks D (decayed) berjumlah 117, M (Missing) berjumlah 7, dan F (filling) berjumlah 2, sehingga indeks DMF-T ratarata pada 59 siswa SMP Kristen 67 Bahu Manado sebesar 2,13 yang didapat dari:

$$
\frac{117+7+2}{59}=2,13
$$

Berdasarkan dari kriteria WHO, indeks ini berada pada kategori status karies rendah. Tabel 5 menunjukkan distribusi

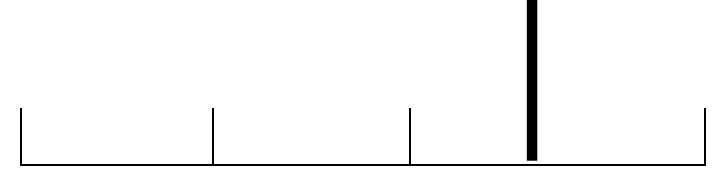

status karies berdasarkan jenis kelamin. Data hasil penelitian, indeks DMF-T terlihat baik pada siswa perempuan maupun siswa laki-laki yaitu berada pada kategori rendah. Indeks DMF-T siswa perempuan didapat dari:

$$
\frac{62+6+0}{29}=2,34
$$

Sedangkan indeks DMF-T pada lakilaki:

$$
\frac{55+1+2}{30}=1,93
$$


Hasil menunjukkan bahwa rata-rata indeks DMF-T pada siswa perempuan lebih tinggi dibandingkan dengan siswa laki-laki. Hasil DMF-T berdasarkan usia terlihat ada perbedaan pada siswa berusia 11 tahun dibandingkan dengan kelompok usia lain (Tabel 6).

Tabel 5. Distribusi status karies berdasarkan jenis kelamin

\begin{tabular}{llllll}
\hline $\begin{array}{l}\text { Jenis } \\
\text { kelamin }\end{array}$ & D & M & F & Skor & Kategori \\
\hline $\begin{array}{lllll}\text { Perempuan } \\
\text { Laki-laki }\end{array}$ & 62 & 6 & 0 & 2,34 & Rendah \\
\hline Total & 55 & 1 & 2 & 1,93 & Rendah \\
\hline
\end{tabular}

Tabel 6. Distribusi status karies berdasarkan usia

\begin{tabular}{llllll}
\hline Usia & D & M & F & Skor & Kategori \\
\hline 11 tahun & 4 & 2 & 0 & 1,5 & Rendah \\
12 tahun & 37 & 2 & 0 & 2,16 & Rendah \\
13 tahun & 35 & 1 & 2 & 1,9 & Rendah \\
14 tahun & 41 & 2 & 0 & 2,52 & Rendah \\
\hline Total & 117 & 7 & 2 & 2,13 & Rendah \\
\hline
\end{tabular}

Tabel 7. Tabel menurut kategori DMF-T

\begin{tabular}{lcc}
\hline Kategori & (n) & $\mathbf{( \% )}$ \\
\hline Sangat rendah & 31 & 53 \\
Rendah & 9 & 15 \\
Sedang & 12 & 20 \\
Tinggi & 4 & 7 \\
Sangat tinggi & 3 & 5 \\
\hline Total & 59 & 100 \\
\hline
\end{tabular}

\section{BAHASAN}

Hasil penelitian tingkat pengetahuan siswa tentang kebersihan gigi dan mulut pada siswa SMP Kristen Bahu Manado tergolong tinggi yaitu 94,45\%. Tingkat pengetahuan dibagi menurut jenis kelamin dan usia. Pada siswa perempuan didapatkan hasil 94,65\% dan 92,42\% pada siswa lakilaki. Pada kelompok usia didapatkan siswa berusia 11 tahun 93,75\%, pada siswa usia 12 tahun 87,91\%, dan pada siswa usia 13 tahun 90,75\% serta pada siswa usia 14 tahun 91,62\%. Keseluruhan hasil yang di dapat termasuk pada kategori yang tinggi dan disimpulkan tingkat pengetahuan siswa SMP Kristen Bahu Manado tergolong tinggi Hasil penelitian indeks DMF-T pada siswa SMP Kristen 67 Bahu Manado masukdalam kategori rendah. Seperti yang kitaketahuibahwa karies gigi dapat disebabkan oleh beberapa faktor yaitu host, agen, substrat, dan waktu. Faktor-faktor lain yang juga mempengaruhi pembentukan karies gigi yaitu pengalaman karies, penggunaan fluor, oral hygiene, umur, jenis kelamin, pola makan dan status sosial ekonomi. ${ }^{8}$

Status karies berada pada kategori rendah dapat dipengaruhi oleh status sosialekonomi. Setelah peneliti melakukan wawancara dengan beberapa siswa diketahui bahwa pekerjaan orang tua dari subjek penelitian ini rata-rata ialah pegawai negeri sipil (PNS), tukang ojek, dan sopir angkutan kota yang berpendidikan terakhir pada jenjang SMA. Hasil wawancara menunjukan, subjek penelitian memiliki latar belakang keluarga dengan status 
golongan sosial-ekonomirendah. Sebuah penelitian di Swedia menunjukan adanya status sosial-ekonomi dengan kejadian karies gigi pada anak usia 12-14 tahun yaitu anak yang berasal dari keluarga golongan sosial-ekonomi yang rendah memiliki resiko karies gigi yang lebih tinggi dibandingkan dengan anak yang berasal dari keluarga dengan golongan status sosial-ekonomi menengah dan tinggi, sehingga dapat dikatakan pendidikan orang tua tentang kebersihan gigi dan mulut dapat mempengaruhi status kariespada gigi anak. ${ }^{5}$ Hasil penelitian ini juga sama dengan hasil penelitian di Zimbabwe pada anak usia 12 tahun yang menunjukan status karies pada anak yang berasal dari daerah pedesaan dengan golongan sosial-ekonomi rendah memiliki status karies yang lebih tinggi dibandingkan dengan anak yang berasal dari daerah perkotaan dengan golongan status sosial-ekonomi yang lebih tinggi. Penelitian serupa jugapernah dilakukan pada anak berusia 12 tahun di Tomohon menunjukan bahwa status karies anak yang berasal dari keluarga dengan status golongan sosial-ekonomi rendah memiliki resiko karies gigi yang tinggi. ${ }^{6,7}$

Hasil yang didapat kan oleh peneliti jelas bertolak belakang dengan hasil dari penelitian-penelitian sebelumnya, karena pada penelitian ini peneliti mendapatkan hasil tingkat karies gigi yang rendah pada subjek penelitian. Perbedaan ini dapat disebabkan oleh kebiasaan menyikat gigi yang cukup baik yang dilakukan oleh subjek penelitian, meskipun tingkat pendidikan atau status sosial ekonomi subjek penelitian dan orang tuanya tergolong rendah, tapi pengetahuan subjek penelitian tentang cara menjaga kebersihan mulut mereka tergolong tinggi. Pengetahuan tentang menjaga kebersihan gigi dan mulut ini bisa saja didapatkan subjek penelitian melalui iklan di media elektronik maupun media cetak, sehingga responden menjadi tahu dan mengerti tentang cara menjaga kebersihan gigi dan mulutnya.

Dari data Riskesdas tahun 2013 memperlihatkan indeks DMF-T meningkat seiring bertambahnya usia. Gigi yang paling awal erupsi adalah gigi yang paling rentan terhadap karies. Hasil penelitian menunjukan rata-rata indeks DMF-T pada usia 12 tahun lebih tinggi dibandingkan dengan usia 13 tahun dan 14 tahun. Hal ini disebabkan pada usia yang lebih dewasa memiliki pengetahuan yang lebih baik sehingga lebih mengerti tentang pemeliharaan kesehatan gigi dan mulut yang baik. ${ }^{4,7}$.

\section{SIMPULAN}

1. Tingkat pengetahuan siswa SMP Kristen 67 Bahu Manado berada pada kategori tinggi.

2. Status karies siswa SMP Kristen 67 Bahu Manado berada pada kategori rendah.

\section{SARAN}

1. Sekolah perlu terus mempertahankan upaya untuk menjaga kesehatan gigi dan mulut pada siswa melalui pemberian pendidikan tentang cara menjaga kesehatan gigi dan mulut.

2. Peran orang tua sangat dibutuhkan dalam memberikan pengertian tentang pentingnya menjaga kesehatan gigi dan mulut pada anak serta mengantar anak secara berkala untuk melakukan pemeriksaan gigi dan mulut.

3. Siswa perlu terus menjaga kesehatan gigi dan mulut mereka agar tetap sehat dan bebas dari karies gigi.

\section{DAFTAR PUSTAKA}

1. Yani RWE, Utami WP. Pengalaman kariesgigi molar pertama permanen berdasarkan riwayat pendidikan taman kanak-kanak. Dentika dental J. 2011;16 (1):41-3.

2. Arvin B. 2012. Karies Gigi pada Anak. ILMU KESEHATAN ANAK.[akses 24 maret 2012]. Available from: hhtp://ilmukesehatangigi.com.

3. Ami A. Pencegahan Primer pada Anak yang Berisiko Karies Tinggi. Fakultas Kedokteran Gigi Departemen Pedodonsia Universitas Sumatera Utara. Maj Ked Gigi (Dent J). 2005;38(3):130-4. 
4. Riset Kesehatan Dasar. Laporan kesehatan gigi dan mulut; 2013

5. Kallestal C, Wall S. Socio-economic effect on caries, incidence data among swedish 12-14-years-olds. Swedia. 2002

6. Walla HC, Wicaksono DA, Tambunan E. Gambaran status karies gigi anak usia 11-12 tahun pada keluarga pemegang jamkesmas di kelurahan Tumatangtang I Kecamatan Tomohon
Selatan [Skripsi]. Manado: Universitas Sam Ratulangi; 2013.

7. Mafuvadze BT, Mahachi L, Mafuvadze B. Dental caries and oral health practice amon 12 years old children from low socio-economic status background in Zimbabwe. Pan Afr Med. 2013;12:42.

8. Bahar A. Paradigma Baru Pencegahan Karies Gigi. Jakarta: Universitas Indonesia, 2011; p.21. 